\title{
From a Professional Tribe to a Business Neo- Tribe: Towards a Theory of Consumer-based Lifestyles in the Legal Profession
}

\author{
By Anna Chronopoulou*
}

\begin{abstract}
The transition of the legal profession from a profession to business has exposed the commodification of the legal profession. This affected the way legal services are offered, the structure of the legal profession and its composition. Despite the commodification of the legal profession, the importance of consumption in articulating legal professional identity has gone carefully neglected. The purpose of this paper is to address this absence. This paper proposes that an alternative focus is required in order to shed new light in the formation of legal professional identity. Neo-tribal sociality addresses the importance of consumption in the formation of consumer groups. From this perspective, it provides an alternative focus for conceptualising legal professional identity. It also challenges the social organisation of the legal profession by providing alternative interpretations on issues of gender, class and age.
\end{abstract}

\section{Introduction}

In acknowledging the importance of a consumer focus, the transition from the traditional model to a new managerial model exposed a commodified legal profession and aspects of neo-tribal sociality. However, there is still a notable absence of reference to cultural practices of consumption in the studies of the legal profession, and consequently in the ways in which the profession represents and understands itself. By overlooking the importance of consumption as part of lawyers' lifestyles, neo-tribal sociality is only partially acknowledged. This absence indicates only a partial realisation of the potential of these changes and a lack of understanding that lawyers are also consumers. This poses an additional question of how consumer-based lifestyles are related to legal practice and therefore constitute the platform upon which professional identity can be articulated. The discussion aims to expose the absence of consumption from the existing literature of the profession and demonstrate how a full realisation of consumer aspects of neo-tribalism could provide new perspectives on the formation of legal professional identity. This paper consists of four parts. The first part exposes the gaps of the consumer-focused model. It proposes that a fuller realisation of neo-tribal sociality could provide

*Lecturer, European College of Law, London, UK. 
alternative conceptualisations of legal professional identity. The second, third and fourth parts explore how neo-tribal sociality challenges traditional interpretations of gender, age and class respectively, while constructing new femininities, masculinities and detraditionalised versions of age and class within the organisational context of the legal profession.

\section{Gaps in the Existing Literature of the Legal Profession: The Absence of Consumption}

Issues of lifestyle have always been related to professional identity. In the traditional model of the profession, they were primarily seen as an issue of occupational status. Although of secondary importance, issues of lifestyles had regularly featured in studies of the profession and, traditionally being an amalgamation of occupational and familial status. The transition from Fordism to post-Fordism emphasised the process of consumption over that of production $^{1}$ and placed a greater emphasis on issues of lifestyle ${ }^{2}$ by making lifestyle a $b u z z^{3}$ and business word. The shift within the legal profession was reflected in the promotion of legal services as commodities. This, in turn, led to a consumer focus on legal practice and in studies of the legal profession. As a result, issues of lifestyles begun to assume greater importance in relation to professional identity within the context of legal practice. In particular, the heightened awareness of lifestyles coincides with the transition of the practice of law from profession to business. It gave rise to a body of literature examining the impact of these changes not only on lawyers' working lives but also on their personal lives. These accounts concentrate on issues of quality of life and of work-life balance and introduce issues of lifestyle to the study of lawyers' work, bridging employment and non-employment, ${ }^{4}$ and reflecting the complexities of social life.

The emergence of a commodified profession signalled a consumer focus on lawyers' professional lives. The demanding nature of commodified work was revealed in ways of attracting and retaining clients; of understanding and meeting the diversity of clients' needs; and of issues of measuring successful performance. In turn, these were translated into profit-making attitudes. The increasing demands would require commitment to an exhausting work schedule, tight deadlines, and the carrying out of 'routinised' tasks. ${ }^{5}$ This, in turn, would lead to long working hours ${ }^{6}$ mirroring the long hours culture of the legal profession. Eventually, meeting the demands of increasingly commodified work had a direct impact on lawyers' personal lives. The demands created issues of stress and anxiety, leading to low levels of work

\footnotetext{
${ }^{1}$ Hall $(1996,2001)$.

${ }^{2}$ Slater (2002).

${ }^{3}$ McRobbie.(1994).

${ }^{4}$ Moorhouse (1989).

${ }^{5}$ Menkel-Meadow (1986).

${ }^{6}$ Sommerlad (2002).
} 
satisfaction. This was reflected in poor staff retention, which caused headaches for law firms because of the large numbers of lawyers leaving in search of a better quality of life. Therefore, although the rewards at least in the upper echelons of the profession were high, the standards of lifestyle were extremely low. ${ }^{1}$ Work activities allowed lawyers no time for non-work activities and this accentuated the isolation of professional from social life. Goodrich contends that the professional legal subject faces indifference and adiaphorisation, highlighting the problems of reconciling identity and bonding the social with the professional. ${ }^{2}$ Berney also suggests that increased work obligations did not allow lawyers any time for themselves or for other commitments in lawyers' personal lives, ${ }^{3}$ creating an imbalance and a conflict between professional and personal commitments.

This only exposes one aspect of the commodification of lawyers' lifestyles. There is still a notable lack of reference to the importance of consumption as an aspect of lawyers' lifestyles. Paradoxically, although professional lifestyles are clearly consumer-based, lawyers remain in the sphere of production. They are regarded as producers and clients as consumers, but this accentuates a limited conceptualisation of professional identity. Professional identity does not necessarily correspond to increased consumer focused sociality that the proponents of the changes thesis proclaim. Rather, it remains confined to processes of production through reference to particular lifestyles. In so doing, studies of professional identity stress the impossibilities rather than emphasizing the possibilities open to professional identity through reference to consumption as an aspect of lawyers' lifestyles.

Exposing issues of work-life balance through the prism of commitments promotes specific lifestyles through which professional identity is informed. Notwithstanding the importance of this literature, it nevertheless focuses on family lifestyle choices. Legal professional identity seems to be a fairly unambiguous reflection of factors such as occupation and family status, situating professional identity within the context of production and not of consumption. It is reminiscent of pre-modern social contexts where identity was taken as given, and even in simple or organized modernity where it was relatively stable or static. ${ }^{4}$ Although this conceptualisation is important because because it emphasizes that issues of lifestyle inform professional life, lawyers are portrayed as producers, breadwinners and as family people rather than as consumers. This approach accentuates the limited perspective that lawyers are deeply embedded in the process of production rather than that of consumption. This, in turn, produces a limited theorisation of professional identity, which seems at odds with the postmodern context within which the legal profession now operates.

The suggestion is that the transformations, which occurred in the legal profession because of the rise in consumer society, portray a particular interest

\footnotetext{
${ }^{1}$ Harper (1997).

${ }^{2}$ Goodrich (2000).

${ }^{3}$ Berney (1995).

${ }^{4}$ Chaney (1996).
} 
in the relationship between consumption and professional identity. This creates different ways of exploring professional identity by emphasising the consumerbased context of the profession. It demands the renegotiation of aspects of legal professionalism and an alternative conceptual focus on the interplay between consumption and the way in which professional identity is constructed and articulated.

The transcending boundaries between consumption and production have allowed for increasing interplay between the two. ${ }^{1}$ In the organisational studies literature, this is translated into a negotiation of consumer-based lifestyles within business contexts. This, in turn allows professionals to be seen not only as producers but also as consumers. In the legal profession, recent studies suggest that ideas of consumer-based lifestyles are increasingly associated with selling a career in large law firms. From this perspective, it might seem that consumption has started to be acknowledged as an aspect of lawyers' lifestyles. This has attracted particular attention within the sector of large corporate law firms. The ways in which consumption informs other areas of legal practice remain underdeveloped. Either this creates the impression that other sectors of the profession insist on traditional methods of consumption and thus of socialising, or that consumption is not valued in other sectors. This erodes the ability of consumption to individualise, collectivise and provide for a new articulation of the two in a fragmented legal profession. Bourdieu suggests that consumption either on an institutional or individual level serves as a means of establishing rather than merely expressing distinctions. ${ }^{2}$ Consumption could thus serve as a means of establishing differences and similarities among law firms and chambers in ways of doing business, and exposing differences and similarities between the two branches of the legal profession.

Another point that needs to be considered is the approach taken to individual legal professionals and their personal consumption. Although consumption can relate to issues of consumer-based identification, studies of the profession suggest participation in particular cultural practices of consumption. This again excludes issues of the sociality of the legal profession. Neo-tribal sociality entails aspects of identifications that are played out from one consumer tribe to the next. ${ }^{3}$ Identifications can be perceived not only as processes of disindividualisation, but also of individualisation within the highly individualised context of the modern legal profession. This breaks away from the static interpretation attributed to legal professional identity and provides a different approach. Identifying with a number of consumer tribes can expose the kaleidoscopic nature of legal professional identity and reveal elements of neo-tribalism in the legal profession. Neo-tribal sociality can reveal the formation of different consumer-based collectivities and individualities among legal professionals within legal practice. It has long been established in the cultural studies literature that cultural practices of consumption can be used as

\footnotetext{
${ }^{1}$ Crang and Jackson (2001).

${ }^{2}$ Bourdieu (1984).

${ }^{3}$ Maffesoli (1996).
} 
a narrative of the self. ${ }^{1}$ Participation in a number of consumer tribes can ascribe new meanings to the conceptualisation of the legal professional self and to the overall experience of becoming and being a lawyer. This argument now turns to a discussion of the absence of consumption from accounts on gender, class and age in the literature on the legal profession. The following discussion aims to expose the ways in which the consumer focus of neo-tribal sociality can produce alternate interpretations of gender, class and age within the context of legal practice.

\section{Gender}

Over the last decades, most professions have experienced a transformation in gender composition. Acker remarks that professional environments, institutions and workplaces are deeply gendered. ${ }^{2}$ The legal profession is no exception. The increase in recent years of the number of women entering the profession coupled with the increasing overall number of practising lawyers has formed a mixed picture of the profession in terms of gender. ${ }^{3}$ Despite the growing numbers of women entering the legal profession, ${ }^{4}$ they do not have the same career progression as men. ${ }^{5}$

At this point, it is important to consider the reasons that might have caused these changes as to the gender composition of the profession. In simple, practical and rational terms, it made business sense and cannot be seen separately from the overall transformation of the profession to business, which has occurred in relation to production, regulation and consumption of legal services as a result of the alterations of state or market regulations. The local, regional, national and international context in which the profession now operates created more consumer need for legal services. That in turn, led both to an increasingly fragmented and increasingly specialised profession and created the need for additional lawyers, and thus the presence of women in both branches of the profession. The growing presence and experience of women in the profession has been widely studied and the majority of these studies report that there has been a significant increase in the number of women in the profession over the last three decades, ${ }^{6}$ but that they are underrepresented in its upper echelons and find it more difficult than men to progress. ${ }^{7}$ They are still paid less that, in itself, leads to earlier departure of women from the profession. ${ }^{8}$ The Law Society's reports reflect those of

\footnotetext{
${ }^{1}$ Shields (1992), Featherstone (1991), Glennie and Thrift (1996).

${ }^{2}$ Acker (1990).

${ }^{3}$ Skordaki (1996), Sommerlad (1994), McGlynn (1998a), Sommerlad (2002).

${ }^{4}$ Sommerlad, Duff and Tomlinson (2010).

${ }^{5}$ McGlynn (2003a).

${ }^{6}$ Hull and Nelson (1998).

${ }^{7}$ Webley and Duff (2007).

${ }^{8}$ Kay and Hagan (2005).
} 
academic research that, compared to male lawyers, women face extreme difficulties in the profession. ${ }^{1}$

One of the important contributions made by the feminist project has been the investigation of the masculine culture of law firms and the Bar. Feminist accounts have concluded that women lawyers find it difficult to access the business practices they prefer or even attain the same flexibility as their male colleagues $^{2}$ and have also suggested that practices such as billing, which point to an aggressive, profit-making attitude and are used as a yardstick of success, reflect male patterns of behaviour. ${ }^{3}$ Another important contribution of the feminist project is that elements of lifestyle choices can be negotiated within the profession, which raises the possibility of new routes for the incorporation of alternative consumer-based lifestyles and choices in legal employment. From this perspective, these accounts supplement but also challenge the mainstream analyses that concentrate mainly on the changes thesis rather than the effect of these changes on professional and personal lives. The themes of these feminist studies benefit the argument of this thesis because they provide valuable insights in the way gender identities can be negotiated through aspects of lifestyle.

Most feminist accounts concentrate on the pressures experienced by women lawyers, which they must negotiate with specific emphasis on aspects of lifestyle choice. ${ }^{4}$ McGlynn suggests that the interrelation between professional and personal life is portrayed in the issue of commitment. ${ }^{5}$ In the context of professional life, commitment refers to issues of work obligations, whereas in the context of personal life it refers to family obligations. Kay suggests that this interrelation can produce interruptions in the normal pattern of professional life because of gender. ${ }^{6}$ Sommerlad suggests that commitment and as a result, career progression is more likely to affect women with domestic responsibilities than men. ${ }^{7}$ It is noteworthy that these accounts apparently subscribe to a view of gender as it informs professional lifestyles through an interrelation with personal lifestyles, which in turn reflects structural transformations within legal practice. The problem is that these theorisations address a particular kind of personal lifestyle permeated with professional lifestyle. This produces a rather static image of gender within the context of contemporary legal practice by limiting the sociality of female legal practitioners. ${ }^{8}$ It suggests that the only personal lifestyles that feminists value as being capable of producing gender identities are the familial. This ignores newer modes of femininities and the effects on professional identity. More consumer-oriented lifestyles reveal a de-traditionalised version of gender, which in turn reveals new modes of femininities, again embedded in

\footnotetext{
${ }^{1}$ Sommerlad, Duff and Tomlinson (2010).

${ }^{2}$ Thornton (1996).Webley and Duff (2007).

${ }^{3}$ Slater (2002).

${ }^{4}$ Hull and Nelson (2000.

${ }^{5}$ McGlynn (2000).

${ }^{6}$ Kay (1997).

${ }^{7}$ Sommerlad and Sanderson (1998).

${ }^{8}$ Silius (2003).
} 
occupational status but disassociated from the traditional familial status. Persistence of traditional interpretations of gender based on the amalgam of occupational and familial status erodes individualism and encourages homogenous accounts of gender in the literature on the legal profession.

The issue of commitment because of the interrelation between professional and personal lifestyles has also been linked to issues of accumulation of sociocultural capital and gender in the context of the profession. For example, Kay argues that interruption in professional life, which can arise as a consequence of gender in any profession, can reduce women's competitive position and personal networks, and this will ultimately have an effect on their career progression. ${ }^{1}$ Commitment is proportional to socio-cultural capital. Sommerlad suggests that Bourdieu's concept of cultural capital is more appropriate in conveying meaning to the relative worth of individuals in the solicitors' profession. It extends beyond the formal skills and education accumulated through training to the socialisation. ${ }^{2}$ Sommerlad also suggests that cultural capital establishes a link between women's skills and qualities and their treatment in a gendered labour market. ${ }^{3}$ Therefore, the concept underlines that while discrimination may not be explicit, there are practices which reinforce gender hierarchies in the legal profession. ${ }^{4}$ These accounts argue that masculinity is the core cultural capital of the legal profession. There is also the suggestion that commitment extends to issues of social capital and thus informs gender hierarchies in the legal profession. Bourdieu defines social capital as resources based on connection, networks and group membership used in the pursuit of advancement. ${ }^{5}$ Socialisation practices intertwine with the question of of commitment in lawyers' professional lives. Thornton suggests that socialisation practices rely heavily on male relationships, reinforcing male collegiality within the organisational context of the profession and disadvantaging women. ${ }^{6}$ Sommerlad emphasises the collegial relations in terms terms of participation in socialisation practices and, as with cultural capital, she concludes that masculinity is the core social capital in the legal profession. ${ }^{7}$ This supports the conclusions of the aforementioned authors and represents a common theme running through feminist accounts of the legal profession. Despite the valuable insights these accounts offer, they do not provide any possibility for individualised femininities in the profession. This suggests that the majority of the feminist project's claims in existing literature see women as a homogenous group and deny or overlook the very possibility of differentiation, which those accounts were set out to achieve in the first place.

Despite the suggestion with respect to socio-cultural capital, Skeggs argues that women have demonstrated strategies of socio-cultural capital accumulation, which suggest different theories of gender and individualised

\footnotetext{
${ }^{1}$ Kay (1997).

${ }^{2}$ Sommerlad (2002).

${ }^{3}$ Sommerlad(1998).

${ }^{4}$ Hall $(1996,2001)$.

${ }^{5}$ Bourdieu (1984).

${ }^{6}$ Thornton (1996).

${ }^{7}$ Hall $(1996,2001)$.
} 
femininity. ${ }^{1}$ The interpretation of socio-cultural capital in feminist accounts seems rather problematic. For instance, quoting Halford and Savage, Sommerlad suggests that exactly what constitutes cultural capital in postmodern contexts is not fixed. ${ }^{2}$ However, Savage clearly stated that practices of consumption and image or even image-based consumption in terms of personal appearance are matters of cultural capital, especially in the postmodern context. ${ }^{3}$ Despite Savage's suggestion that cultural capital extends to consumer-based lifestyle issues, feminist writing treats both cultural and social capital as being fixed only in the field of legal practice, rather than also being part of the social. Therefore, in Maffesolian terms, their subjects are precluded from demonstrating their ability to adapt to their environment using socio-cultural capital, thus producing alternative gender meanings. In addition, most feminist accounts treat gender as the only relevant dimension in social and cultural capital. Apart from producing limited interpretations of professional identity, this also limits conceptualisation of gender. According to Butler, gender retains a performative aspect ${ }^{4}$ and, in this sense, becomes a cultural practice. ${ }^{5}$ Thus, gender can assume different meanings through different practices of consumption. The Maffesolian theory of neo-tribal sociality ignores gender. Gender, as an expression of identity, is replaced by the notion of identifications, but it is exactly the existence of consumer-based identifications that can express different forms and expressions of gender within legal practice. Cultural practices of consumption become an added dimension to socio-cultural capital by acknowledging sociality, which informs gender. The argument now turns to illustrative examples of the absence of consumer-based lifestyles from the relevant accounts in the legal profession on issues of age.

\section{Age}

The previous section revealed that the relationship between aspects of professional and private life informs the legal professional identity on issues of gender. The examination of the literature revealed that the neglect of consumer-based lifestyles from the accounts of gender devalued femininity and individualism. Accounts of new entrants to the profession share similar affinities with the analyses of gender. Before going into an examination of some of these accounts, a point needs to be made on the age composition of the profession. The assertion is that the transformations that have occurred in the composition of the profession resulted in a transformation in terms of age. For example, Abel suggests that the relaxation on restrictions on access

\footnotetext{
${ }^{1}$ Skeggs (1997).

${ }^{2}$ Sommerlad (1998).

${ }^{3}$ Savage et al (1992).

${ }^{4}$ Butler (1990).

${ }^{5}$ McRobbie.(1994).
} 
transformed the profession from an elderly to a relatively youthful profession. ${ }^{1}$ It is noteworthy, however, that given the time required for the completion of studies in other jurisdictions, the age difference could potentially be more striking than in the UK. ${ }^{2}$ Shiner's age classification into early, late and mature entrants varying from 23 to 29 or older respectively, ${ }^{3}$ coupled with the difficulties faced by mature students in entering the profession, ${ }^{4}$ and age being among the decisive selective criteria for employment in the profession, ${ }^{5}$ paint a a youthful picture of today's legal profession.

Academic studies of young lawyers discuss and focus on transition from legal education to the legal profession and therefore a legal career. Cohort studies concentrate on gaining access to the profession and the difficulties that young students face. These difficulties are not only due to the demanding entry requirements, but also to the popularity of the subject among the student population, ${ }^{6}$ increasing competition. A few qualitative accounts reveal that these difficulties are suggestive of discrimination. For instance, Boon et al suggest that differentiation and subordination that occur within the profession reflect the firms' and chambers' preferences as opposed to the individual young lawyer's choices and aspirations in entering legal practice. ${ }^{7}$ Furthermore, the accounts of youth in the profession are important because they provide valuable information on the profession's expectations of young lawyers, while exposing the plurality of legal styles that characterise contemporary legal practice. Another important point that these accounts address is the ways in which young lawyers are socialised in the profession. These accounts also address young lawyers' expectations of the firms and chambers and the way young lawyers are valued in the profession. This last point is important because it provides valuable insights into the construction of professional identity through young lawyers' choices. These choices become socialised in legal practice. In the commercialised and entrepreneurial context within which the legal profession operates, the new entrepreneurs are viewed as more flexible and innovative, bringing with them new entrepreneurial and managerial ideas. ${ }^{8}$ Conversely, new entrepreneurs could be also viewed with suspicion. ${ }^{9}$ Due to enhanced competition, this creates tensions between younger and older members within the hierarchies of the profession ${ }^{10}$, which is not just a 'generation gap' issue. It also raises another point. Young lawyers are perceived as less committed and therefore devalued until proper value is conveyed upon them through the learning mode of the profession.

\footnotetext{
${ }^{1}$ Abel (1987, 1988, 2003).

${ }^{2}$ Collier (2005).

${ }^{3}$ Shiner (2000).

${ }^{4}$ Francis and McDonald (2000).

${ }^{5}$ Lee (2000).

${ }^{6}$ Rolfe and Anderson (2003).

${ }^{7}$ Boon, Duff, and Shiner (2001), Boon, Flood and Webb (2005).

${ }^{8}$ Seron (1992).

${ }^{9}$ Hall (1996, 2001).

${ }^{10}$ See Abel (1988).
} 
Educational qualifications and socialisation into a professional culture are valued as aspects of young lawyers' lifestyles but raises concerns over the sociality of young lawyers. It produces static interpretations of young lawyers' identities, because it does not reveal any of the consumer-based aspects of professional identity. It also neglects how aspects of young lawyers' consumerbased lifestyles influence the construction of professional identity. It would be misleading to suggest that young lawyers' lifestyles are merely a mirror of consumer habits but, as Thornton suggests, consumption constitutes a sometimes informal and sometimes very formal infrastructure or backbone of the legal profession. ${ }^{1}$ In this sense, the postmodern paradox does not lie in the commodification of the legal profession, rather in the conceptualisation of a commodified profession without addressing aspects of consumer-based lifestyles. This reinforces the assumption that young lawyer's consumer-based lifestyles are undervalued. This approach sits uneasily with that taken in advertising material, which refers to consumption as an aspect of youth lifestyles, creating the impression that young lawyers' lifestyles are tremendously valued. ${ }^{2}$ Collier explores the ways large law firms promote training contracts for solicitors using images of consumption and consumerbased lifestyles related to youth culture ${ }^{3}$. He concludes that consumption related to youth lifestyles is acknowledged as informing legal professional identity ${ }^{4}$. Notwithstanding the importance of Collier's work, there are aspects that his studies do not cover. For instance, he focuses solely on large law firms and does not explore how these aspects are played out in other segments of the legal profession, including the reality of being a young solicitor in a small or medium firm, or of being a barrister. Neither does he investigate how young legal professionals manage these consumer-based lifestyles in legal practice and whether this sheds light on the construction of professional identity. These omissions suggest that the experience of consumption is strictly confined to young corporate lawyers' lifestyle. Another area worthy of investigation is whether consumer-based youth lifestyles comply with the entrepreneurial spirit of the legal profession at large and create new ways of doing business.

It has long been established in accounts of youth culture that young people construct their identities and identifications through consumption. Maffesoli argues that neo-tribal sociality entails the consumer-based identifications exposed in youth groups, ${ }^{5}$ and therefore consumption may well provide an alternative upon which young lawyers' identities and identifications could be constructed in the profession. A fuller realisation of neo-tribal sociality could expose the importance of consumer-based youth lifestyles in the articulation of the legal professional identity. This could also expose different ways of doing business by filling the gaps in the literature of the legal profession. Professionalisation processes amount to the socialisation of young lawyers in

\footnotetext{
${ }^{1}$ Thornton (1996).

${ }^{2}$ Collier $(2005,2006)$.

${ }^{3}$ Menkel-Meadow (1986).

${ }^{4}$ Collier $(2005,2006)$.

${ }^{5}$ Maffesoli (2007).
} 
the legal professional culture. Although this amounts to a form of neo-tribal sociality, it would be useful to explore how other aspects of neo-tribal sociality that young people's lifestyles expose can be played out within the organisational context of legal practice.

\section{Class}

The previous sections attempted to address the absence of consumer-based lifestyles from accounts on gender and age in the legal profession and its effect on the theorisation of these markers of identity. This section analyses the general themes on the formation of class in the profession in terms of admission and recruitment. It also reveals how class formation has been retained through participation in certain practices of consumption as a means of socialisation practices in legal culture bringing together studies on class analysis in the legal profession and cultural studies and addresses the absence of consumer-based lifestyles from the class analysis of lawyers.

The majority of analyses of class in the legal profession are unanimous in suggesting that the legal profession is essentially middle class and this is perpetuated by exclusionary practices. In a profession obsessed with status and elitism, exclusionary practices constitute a mechanism commonly found amongst professions and organisations to perpetuate themselves in their own image. ${ }^{1}$ The middle class composition of the profession has been solidified by mechanisms such as recruitment, which reinforces class distinctions within the hierarchy of the profession. For example, many commentators suggest that the upper echelons of the profession, namely the $\mathrm{Bar}^{2}$ and large law firms, remain predominantly middle class and white, whereas, other areas of practice and the lower ranks of the profession, are more varied in terms of class and race. For example, Boon argues that: "when it comes to selection, segmentation on grounds of class begins immediately." 3 This is due to law firms' preferences regarding recruitment. It is widely depicted in class analysis of the profession that large firms, both City and provincial, prefer a certain type of candidates. ${ }^{4}$ For instance, particular preference is shown to candidates suggestive of middle class background rather than to candidates who are of lower class backgrounds. ${ }^{5}$ Large City firms can recruit the best candidates and finance them through their studies, ${ }^{6}$ even if they are not disadvantaged financially.

Recruitment also relates to issues of socio-cultural capital, which in turn are suggestive of class issues. For example, preference to the best candidates means those coming from old universities, therefore possessing cultural capital, which is again suggestive of middle class background. Nevertheless, it is

\footnotetext{
${ }^{1}$ Nicholson (2005.)

${ }^{2}$ Zimdars (2010).

${ }^{3}$ Boon, Duff and Shiner (2001).

${ }^{4}$ Rolfe and Anderson (2003).

${ }^{5}$ Baker (2003).

${ }^{6}$ Vignaendra (2001).
} 
promoted by large law firms as sound practices of recruitment. ${ }^{1}$ For instance, Thornton notes that class membership shapes the nature of the legal profession in Australia and promotes the culture of homosociability in both branches of the profession. ${ }^{2}$ Although, this hints at issues of class, it also signals the importance of contacts and networking within the profession. As research reveals, in terms of recruitment, personal contacts are important in either getting a training contact or even getting access to relevant information on the profession, by either having an insider in the firm or family members in the profession. ${ }^{3}$ This means that those with greater access to socio-cultural capital are in an advantageous position if compared to those who do not possess the necessary contacts. This, however, is also suggestive of middle class background. It is usually the middle class that have greater access to sociocultural capital.

Socio-cultural capital in the legal profession is produced through socialisation and collective associations involving consumption in pursuit of business. Following Bourdieu, the ways of accomplishing certain leisure practices may articulate and negotiate aspects of class habitus. ${ }^{4}$ As Skeggs suggests "in the conversion from cultural to economic capital the middle classes are likely to be the ones who have access to the social networks", which enable this conversion. ${ }^{5}$ Cultural practices of consumer-based lifestyles usually usually associated with lawyers and which are used and converted to economic capital through socialisation practices in the legal profession include: wine tasting, drinking, theatre, opera, and sports. These are referred to as the familiar leisure-based consumptions and activities relevant to lawyers' lifestyles and which confer middle class status. The problem is that focussing on certain forms of consumption and leisure practices does not allow for the renegotiation of class in the legal profession. Although, some accounts refer to these particular socialisation practices, which are termed acceptable for the middle class formation of the profession, they do not refer to other types of consumption to find out how other consumption informs legal professional identity. This again underplays the role of consumption in the construction of legal professional identity and precludes lawyers' sociality. It does not accord with the new entrepreneurial and highly commodified aspects of the contemporary legal profession.

Middle class formation has been related to the pursuit of aestheticisation of people through consumption and has been associated with professional groups. For example, the study by Savage et al drew on the notion of Bourdieu's habitus. ${ }^{6}$ It concentrated on the consumption habits of upper middle class and middle class occupational groups examining methods of identity formation within professional groups through patterns of consumption. Their research

\footnotetext{
${ }^{1}$ McRobbie.(1994).

${ }^{2}$ Thornton (1996).

${ }^{3}$ Sommerlad et al (2010).

${ }^{4}$ Bourdieu (1990).

${ }^{5}$ Skeggs (2004).

${ }^{6}$ Savage et al (1992).
} 
suggests that consumer-based aspects associated with high culture are permeated with consumptions associated with low culture. Furthermore, Featherstone suggests that the new entrepreneurs construct their pleasure in the form of calculating hedonism through the use of leisure. ${ }^{1}$ From this perspective, they maximize their productivity and market value. In the organisational context of the legal profession, the use of leisure and consumption patterns could expose renegotiations of class formation, class distinctions and identifications between the different segments of the legal profession and on individual level. Although this is reminiscent of the Bourdieusian approach, it also emphasises aspects of neo-tribal sociality through exposing multiple patterns of consumption. Neo-tribal sociality presupposes participation in a variety of consumer groups, or tribes. Although neo-tribal sociality does not perceive class as being of primary importance, participation in a variety of consumer tribes relates to socio-economic position, which could inform class identification. This interpretation breaks away from traditional interpretations of class within the context of legal practice and legal profession, suggesting that class can be constructed through educational qualifications and access to certain aspects of socio-cultural capital. Neo-tribal sociality could expose different aspects of socio-cultural capital that could be a product of multiple patterns of consumption. The suggestion here is that in today's legal profession, class involves aspects of more sensuous consumptions that are more aligned to the renegotiation of middle class than accounts of the legal profession seem to suggest.

\section{Conclusion}

Despite the influence of consumerism on the transition to a commodified legal profession, the importance of consumption in informing professional identity remains elusive, and this has consequences on the analysis of legal professional identity. This paper sought to address this absence by exposing gaps in the existing literature concerning consumer-based lifestyles. The main purpose of the paper was to explore further the perception of consumption within the context of the legal profession. This led to an examination and discussion of the key accounts in the legal profession on gender, class and age. In doing so, it proposed an alternative focus in exploring legal professional identity, that of neo-tribal sociality.

\section{References}

Abel, R.L. (1987). 'The Transformation of the American Legal Profession', Law and Society Review 20(1):7-17.

Abel, R.L. (1988). The Legal Profession in England and Wales. Oxford: Basil Blackwell.

Abel, R.L. (2003). English Lawyers between the Market and the State: Politics of

\footnotetext{
${ }^{1}$ Featherstone (1991).
} 
Vol. 1, No. $1 \quad$ Chronopoulou: From a Professional Tribe to a Business Neo-Tribe...

Professionalism. Oxford: Blackwell.

Acker, J. (1990). 'Hierarchies, Jobs, Bodies: A Theory of Gendered Organisations, Gender and Society 139-158.

Baker, C. (2003). 'Chain Reaction', Law Gazette.

Berney, C. (1995). "Quality of Life and the Legal Profession", International Journal of the Legal Profession 2(2): 253-261.

Boon, A., Duff, L. and M. Shiner. (2001). 'Career Paths and Choices in A Highly Differentiated Profession: The Position of Newly Qualified Solicitors', Modern Law Review 64(4): 563-594

Boon, A., Flood, J. and J. Webb (2005). 'Postmodern Professions: The Fragmentation of Legal Education and the Legal Profession' Journal of Law and Society 32(3):473-492.

Bourdieu, P. (1984). Distinction: A Social Critique of the Judgement of Taste. London: Routledge and Kegan Paul.

Bourdieu, P. (1990). The Logic of Practice. Cambridge: Polity Press.

Butler, J. (1990). Gender Trouble: Feminism and the Subversion of Identity. London: Routledge.

Chaney, D. (1996). Lifestyles. London: Routledge.

Collier, R. (2005) 'Be smart, be successful, be yourself...? Representations of the training contract and trainee solicitors in advertising by large law firms', International Journal of the Legal Profession 12 (1):51-92

Collier, R. (2006). 'Peter's Choice: Issues of Identity, Lifestyle and Consumption in Changing Representations of Corporate Lawyers and Legal Academics'. In Greenfield, S. and G. Osborne (eds) Readings in Law and Popular Culture. London: Routledge.

Crang, P. and P. Jackson (2001). 'Geographies of Consumption'. In Morley, D. and K. Robins (eds). British Cultural Studies, 327-42. Oxford: Oxford University Press.

Featherstone, M. (1991). Consumer Culture and Postmodernism. London: Sage.

Francis, A., and I. McDonald (2000). 'All Dressed up and Nowhere to Go? Part Time Law Students and the Legal Profession'. In Thomas, P. Discriminating Lawyers. London: Cavendish.

Glennie, P. and N. Thrift (1996). 'Consumption. Shopping, Gender'. In Wrigley, N. and M. Lowe (eds) Retailing, Consumption and Capital: Towards the New Retail Geography,221-237. Harlow, Essex: Longman.

Goodrich, P. (2000). 'Law Induced Anxiety: Legists, Anti-Lawyers and the Boredom of Legality', Social and Legal Studies 9 (1):143-160.

Hall, S. (1996). "Introduction: Who Needs 'Identity'?". In Hall, S. and Du Gay, P. (eds) Questions of Cultural Identity 1-17, London: Sage.

Hall, S. (2001). "For Allon White: Metaphors of Transformation". In D. Morley \& K.H. Chen (eds) Stuart Hall: Critical Dialogues in Critical Studies 287-308. London: Routledge.

Harper, J.R. (1997). 'Global Practice Now and in the Future'. In Harper, J.R. (eds) Global law and Practice. Amsterdam: Kluwer.

Hull, K. and R.L. Nelson (1998). 'Gender Inequality in Law: Problems of Structure and Agency in Recent Studies of Gender in Anglo-American Legal Professions' Law and Social Inquiry 23(3): 681-705.

Hull, K. and R.L Nelson (2000). 'Assimilation Choice or Constraint? Testing Theories of Gender Differences in the Careers of Lawyers', Social Forces 79 (1): 229-264.

Kay, F. (1997). 'Flight from Law: A competing Risks Model of Departure from Law Firms' Law and Society Review 31(2):301-335.

Kay, F., and J. Hagan (2005). 'Canada, Social Mobility and Hierarchical Structure in 
Canadian Law Practice'. In Felstiner, W. (ed) Reorganisation and Resistance: Legal Professions Confront a Changing World, 281-312. London: Hart.

Lee, R.G. (2000). 'Up or Out'- Means or Ends? Staff Retention in Large Firms'. In Thomas, P. Discriminating Lawyers. London: Cavendish.

Maffesoli, M. (1996). The Time of the Tribes: The Decline of Individualism in Mass Society. London: Sage.

Maffesoli, M. (2007). 'Tribal Aesthetic'. In Cova, B. Kozinets, R. V. and A. Shankar (2007) Consumer Tribes, 27-34. Oxford: Butterworth- Heinemann.

McGlynn, C.(1998a). Legal Feminisms: Theory and Practice. Aldershot: Ashgate.

McGlynn, C.(1998b). The Woman Lawyer: Making the Difference. London: Butterworths.

McGlynn, C. (2000). 'The Business of Equality in the Solicitors' Profession', Modern Law Review 63(3): 442-456

McGlynn, C. (2003a). 'The Status of Women Lawyers in the United Kingdom'. In Schultz, U. \& Shaw, G. (eds) (2003) Women in the World's Legal Professions, 139-148. Oxford: Hart.

McGlynn, C.(2003b). 'Strategies for Reforming the English Solicitors' Profession: An Analysis of the Business Case for Sex Equality'. In Schultz, U. \& G. Shaw (eds) (2003) Women in the World's Legal Professions, 159-174. Oxford: Hart.

McRobbie, A. (1994). Postmodernism and Popular Culture. London: Routledge.

Menkel-Meadow, C. (1986). 'Exploring a Research Agenda of the Feminisation of the legal Profession: Theories of Gender and Social Change' Journal of Law and Social Inquiry 24 (4): 289-319.

Moorhouse, H. (1989). 'Models of Work, Models of Leisure'. In Rojek, C. (eds) (1989) Leisure for Leisure: Critical Essays. London: Macmillan.

Nicholson, D. (2005). 'Demography, Discrimination and Diversity: A New Dawn for the British Legal Profession' International Journal of the Legal Profession 12(2): 201-228.

Rolfe, H. and J. Anderson (2003). 'A Firm Choice: Law Firms' Preferences in the Recruitment of Trainee Solicitors' International Journal of the Legal Profession 10 (3) 315-334.

Savage, M., Barlow, J., Dickens, P. and T. Fielding (1992). Property, Bureaucracy and Culture: Middle Class Formation in Contemporary Britain. London: Routledge.

Seron, C. (1992). 'Managing Entrepreneurial Legal Services: The Transformation of Small- Firm Practice'. In Nelson, R. L., Trubek, D. and R. Solomon (eds) (1992) Lawyers' Ideals/Lawyers' Practices: Transformation in the American Legal Profession. Ithaca and Cornell: Cornell University Press.

Silius, H. (2003). 'Making Sense of Gender in the Study of Legal Professions' International Journal of the Legal Profession 10 (2):135-148.

Shields, R. (1992). Lifestyle Shopping: The Subject of Consumption. London: Routledge.

Shiner, M. (2000). 'Young Gifted and Blocked! Entry to the Solicitors' Profession'. In Thomas, P. Discriminating Lawyers. London: Cavendish.

Skeggs, B. (1997). Formations of Class and Gender: Becoming Respectable. London: Sage.

Skeggs, B. (2004). Class, Self and Culture. London: Routledge.

Skordaki, E. (1996). 'Glass Slipper and Glass Ceilings: Women in the Legal Profession' International Journal of the Legal Profession 3 (1/2):7-37

Slater, D. (2002). Consumer Culture \& Modernity. Cambridge: Polity Press.

Sommerlad, H. (1994). 'The Myth of Feminisation: Women and Cultural Change in 
Vol. 1, No. 1 Chronopoulou: From a Professional Tribe to a Business Neo-Tribe...

the Legal Profession' International Journal of the Legal Profession 1(1):31-53.

Sommerlad, H. (1998). 'The Gendering of the Professional Subject: Commitment, Choice and Social Closure'. In McGlynn, C. (ed) (1998) Legal Feminisms: Theory and Practice,3-21. Aldershot: Ashgate.

Sommerlad, H. (2002). 'Women Solicitors in a Fractured Profession: Intersections of Gender and Professionalism in England and Wales', International Journal of the Legal Profession 9 (3): 213-234.

Sommerlad, H. and P. Sanderson (1998). Gender, Choice and Commitment. Aldershot: Ashgate.

Sommerlad, H. Duff, L. and J. Tomlinson (2010). Diversity in the Legal Profession in England and Wales: A Qualitative Study of Barriers and Individual Choices, Legal Services Board.

Thornton, M. (1996). Dissonance and Distrust: Women in the Legal Profession. Melbourne: Oxford University Press.

Vignaendra, S. (2001). 'Social Class and Entry into the Solicitors' Profession' Research Study 41 London: The Law Society.

Webley, L. and L. Duff (2007). 'Women as a Barometer for Problems within the Legal Profession-Time to Put Values before Profits?' Journal of Law and Society 34 (3):374-402.

Zimdars, A. (2010). 'The Profile of Pupil Barristers at the Bar of England and Wales 2004-2008' International Journal of the Legal Profession 17(2):117-134. 